\title{
Research
}

\section{Phytochemical studies and in vitro activity of Asparagus racemosus}

\author{
Arjun Kafle, Surya K. Kalauni, Mangala Devi Manandhar* \\ Central Department of Chemistry, Tribhuvan University, Kirtipur, Kathmandu, Nepal
}

\begin{abstract}
Phytochemical and biological screening of root of Asparagus racemosus was studied. The brine shrimp bioassay of its various extracts showed that the methanol $(\mathrm{MeOH})$ extract was biologically active. The column chromatography of hexane, acetone and methanol extracts resulted in the isolation of 9hexadecanoic acid-9-octadecenylester (Z,Z), $\beta$-Sitosterol, stigmasterol-3-O- $\beta$-D-glucopyranoside and diosgenin. The estimation of saponin in the root of Asparagus racemosus has also been carried out.
\end{abstract}

Keywords: Asparagus racemosus, brine shrimp bioassay, diosgenin, saponin

\section{Introduction}

Asparagus racemosus is a member of family Asparagaceae. ${ }^{1}$ It is commonly known as shatavarin and Kurilo in Nepali. This plant is cosmopolitan in nature and is found more abundant in the jungle of Central Terai region and Himalayan at the height of $165 \mathrm{~m}$ to $2200 \mathrm{~m}^{2}$. It has been specially recommended in cases of threatened abortion and as a galactogogue. ${ }^{1}$ Root of asparagus has been referred as bitter-sweet, emollient, cooling, nerve tonic, aphrodisiac, diuretic, rejuvenating, carminative, and stomachic antiseptic and tonic. It is reported to be useful against diarrhoea, dysentery and in general debility. ${ }^{3}$ Saponins and an alkaloid asparagamine A exhibit antioxytocin activity which supported the traditional claim of $A$. racemosus as remedy for preventing miscarriage. ${ }^{4}$ Root of this plant was selected for chemical and biological analysis. In the present investigation, phytochemical and biological screening, isolation and characterization of biologically active chemical constituents from the roots was carried out and the percentage of saponin in A. racemosus have been estimated.

\section{Materials and methods}

\section{Collection of Plant Material}

The roots of the Asparagus racemosus were collected from a farm of Chitwan district and identified by Prof. Dr. R. P. Chaudhary of Central Department of Botany, Tribhuvan University.

\section{Extraction}

About $850 \mathrm{~g}$ of dried plant material was extracted in soxhlet extractor using solvent of increasing polarity. Successive extraction of dried plant material by hexane $(500 \mathrm{ml} \times 3)$, acetone $(500 \mathrm{ml} \times 3)$ and methanol $(400 \mathrm{ml} \times 3)$ yield $2.05 \mathrm{~g}, 9.4 \mathrm{~g}$ and $29 \mathrm{~g}$ extract respectively.

\section{Phytochemical Screening}

The method employed for phytochemical screening was based on the procedure put forward by Prof. I. Ciulei. ${ }^{5}$ By using different specific reagents, the presences of main groups of natural products were analyzed in hexane, acetone and methanol extracts.

*Correspondence author: mangalamanandhar@ntc.net.np 


\section{Biological Screening of Asparagus racemosus}

Biological screening involves the study of the effect of the crude plant extracts fractions and isolated compounds at arbitrarily fixed dose levels in a species of organism and prediction of its effect over the entire dosage range. The present research involves the screening of each fraction of the extract for their antibacterial and brine-shrimp toxicity activity.

\section{Brine Shrimp Bioassay}

The Hexane, Acetone and Methanol extracts were tested for their pharmacological potential by brine shrimp bioassay. The procedure followed for the brine-shrimp toxicity assay was carried out according to Mayer et al. $^{6}$ Procedure which involve determination of $\mathrm{LC}_{50}$, the lethal concentration dose required to kill $50 \%$ of the shrimps.

\section{Anti microbial Screening}

The ability to kill or inhibit the growth of pathogenic microorganisms was evaluated by anti microbial screening of the plant extracts. The three different fractions obtained were screened for its antibacterial activity by determining the Zone of Inhibition (ZOI), with the help of scale against tested organisms by agar well diffusion method given by Dingle et al. ${ }^{7}$ The diameter of zone of inhibition (ZOI) measures for the estimation of potency of the antimicrobial substances. In this work Staphylococcus aureus, Escherichia coli, Klebsiella pneumoniae, Salmonella typhi. Salmonella paratyphi, Proteus mirabilis, Shigella dysentriae, Pseudomonas aeruginosa, Klebsiella oxytoca pathogenic bacteria were selected.

\section{Separation of Compounds}

Compounds were separated from Hexane, Acetone and Methanol extracts by column chromatography. In this process $(1.16 \mathrm{~g})$ hexane, and $(8.0 \mathrm{~g})$ acetone extract were loaded in a silica gel $(85 \mathrm{~g}$, E-merck, 60$120 \mathrm{mesh}$ ) packed column having internal diameter $4 \mathrm{~cm}$ with the adsorbent height $45 \mathrm{~cm}$ and were eluted with gradients of hexane, ethyl acetate and methanol to obtain number of fractions containing compounds $\mathrm{AM}_{100}, \mathrm{AM}_{101}, \mathrm{AM}_{102}$ and $\mathrm{AM}_{103}$.

\section{Determination of saponin content}

Saponin content on root of $A$. racemosus was estimated by Roth Rock et. al Method. ${ }^{8}$ In this method air dried powered material $(50 \mathrm{~g})$ was extracted with petroleum ether in soxhlet extractor for 20 hours. The defatted powder was then hydrolyzed with $5 \% \mathrm{HCl}$ by refluxing in steam bath for 20 hours. The residue obtained by filtration under suction was washed thoroughly with water to remove last traces of $\mathrm{HCl}$. The product after proper drying was extracted in a soxhlet with petroleum ether for 10 hours. The petroleum ether extract was washed thoroughly with $5 \% \mathrm{NaOH}$ followed by water. The residue obtained on removal of the solvent was dried till to have constant weight. 


\section{Result and discussion}

\section{Phytochemical and biological Screening of Asparagus racemosus}

Phytochemical screening of roots of $A$. racemosus was carried out on the basis of procedure developed by Prof. I. Ciulei. Fatty acids, sterols and triterpenes were identified in the Hexane extract and glycosides, quinines, flavone glycosides, reducing compounds, polyoses and saponin were revealed in methanol and aqueous extract.

Two sets of biological screening brine shrimp bioassay and antimicrobial bioassay were carried out. Brine shrimp bioassay is the simple bioassay useful for screening large number of extracts in the drug discovery from the medicinal plant. The biological activity was evaluated on the basis of their toxicity towards brine shrimp nauplli. ${ }^{\mathbf{9}}$ The procedure followed was of Mayer et al, ${ }^{\mathbf{1 0}}$ was adopted to determine the lethality of plant extract. In this method, the $\mathrm{LC}_{50}$-values $(\mu \mathrm{g} / \mathrm{ml})$ for different fractions were determined and those having $\mathrm{LC}_{50}$ values less than $10^{3}$ are considered to be pharmacologically active. $\mathrm{LC}_{50}$ of hexane, acetone and methanol extracts were found to be $2318.3,1388.2$, and $734.3 \mu \mathrm{g} / \mathrm{ml}$ respectively. The data suggested that methanol fraction could be biologically active for further works.

Antimicrobial inhibition studies of different fractions of root of Asparagus racemosus was carried out at Central Department of Microbiology, Tribhuvan University. The study showed the antimicrobial activity of methanol fraction. Hexane and acetone fractions showed moderate activity.

\begin{tabular}{|c|c|l|l|c|}
\hline SN & Plant Fraction & Organisms & \multicolumn{2}{|c|}{ Zone of Inhibition (mm) } \\
& & & \multicolumn{2}{c|}{ Control } \\
\hline 1. & \multirow{2}{*}{ Hexane } & Staphylococcus aureus & 6 & $\mathbf{1 2}$ \\
\cline { 3 - 5 } & & Klebsiella pneumonia & 6 & $\mathbf{1 2}$ \\
\hline 2. & \multirow{2}{*}{ Acetone } & Staphylococcus aureus & 6 & $\mathbf{1 3}$ \\
\hline \multirow{2}{*}{3.} & \multirow{2}{*}{ Methanol } & Staphylococcus aureus & 6 & $\mathbf{1 5}$ \\
\cline { 3 - 5 } & & Salmonella typhii, & 6 & $\mathbf{1 2}$ \\
\cline { 3 - 5 } & & Salmonella paratyphi & 6 & $\mathbf{1 3}$ \\
\cline { 3 - 5 } & & Shigella dysentriae & 6 & $\mathbf{1 2}$ \\
\hline
\end{tabular}

Table 1: Antimicrobial Study of Different Fractions of $A$. racemosus

$$
\text { Well Diameter }=6 \mathrm{~mm}(0.6 \mathrm{~cm}), \text { Concentration of loaded extract }=50 \mathrm{mg} / \mathrm{ml}
$$

\section{Analysis and Identification of Isolated Compounds}

Chemical constituents were isolated from different extracts by column chromatography.

\section{Compound $\mathrm{AM}_{100}$}

It is a white sticky solid $(9 \mathrm{mg})$, isolated from hexane extract which melts at $\left(77-80^{\circ} \mathrm{C}\right)$ and is insoluble in methanol. One major tailing spot was observed in TLC with $\mathrm{R}_{\mathrm{f}}$ value 0.85 (toluene: EtOAc $=99: 1+$ $\mathrm{CH}_{3} \mathrm{COOH}$ vapor). The compound is UV active. It was found to be 9-hexadecanoic acid-9-octadecanoyl ester, $(\mathrm{Z}, \mathrm{Z})$ having molecular formula $\mathrm{C}_{34} \mathrm{H}_{64} \mathrm{O}_{2}$, on the basis of match factor from EI mass analysis. 


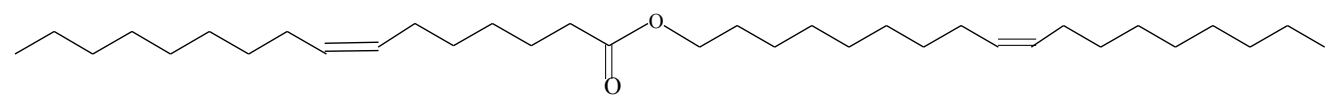

\section{9-Hexadecanoic acid- 9-octadecenyl ester $(Z, Z)$}

\section{Compound $\mathbf{A M}_{101}$}

This compound was extracted from hexane extract. It was dissolved in ethyl acetate and added a few drops of hexane to the solution drop wise till turbid. The solution was kept undisturbed for overnight. White crystalline substance was crystallized. The compound was found to be single spotted on TLC with $\mathrm{R}_{\mathrm{f}}$ value 0.45 (20\% EtoAc in hexane). It was soluble in chloroform and ethyl acetate. The melting point of compound was found to be $132^{\circ} \mathrm{C}$. It gave positive Libermann-Burchard test with greenish red color indicating the compound to be sterol. Same compound was isolated from acetone extract by using $10 \%$ EtOAc in hexane eluting solvent. It was finally identified as to be $\beta$-sitosterol (14 mg) by co-TLC with authentic sample.

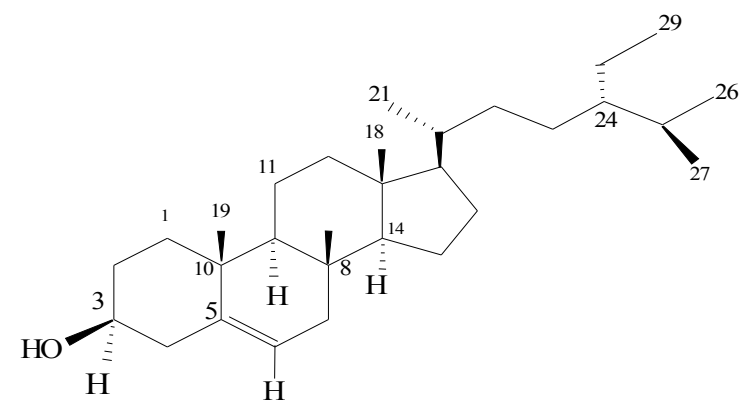

$\beta$-sitosterol

\section{Compound $\mathrm{AM}_{102}$}

Fractions (91-100) obtained by eluting acetone extract by (40\%EtOAc in hexane) resulted a white amorphous compound. TLC of the compound showed a single spot with $\mathrm{R}_{\mathrm{f}}$ value $0.6(15 \% \mathrm{MeOH}$ in $\mathrm{CHCl}_{3}$ ). The compound was found to melt at $294^{\circ} \mathrm{C}$. It was soluble in pyridine and mixture of methanol and chloroform (1:1). Direct comparison with authentic sample, the compound was identified as Stigmasterol-3-O- $\beta$-glucopyranoside (8mg).

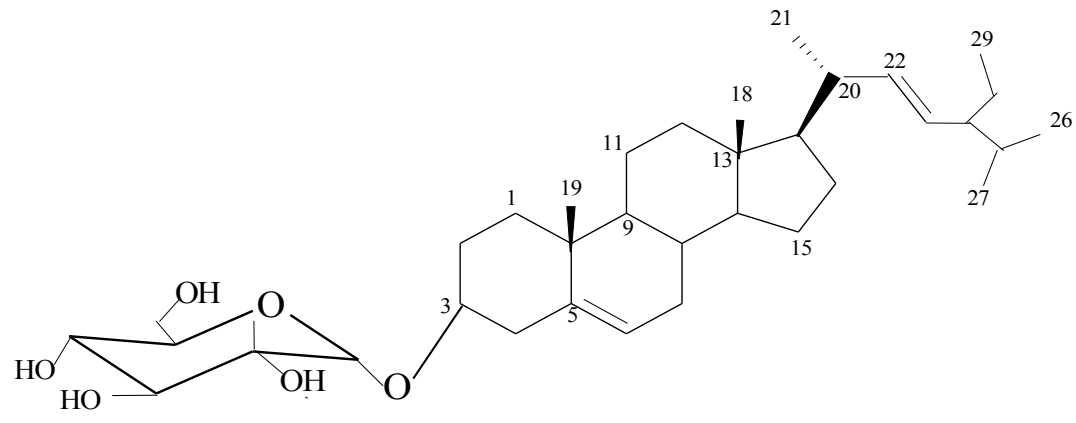

Stigmasterol 3-O-ß-D-glucopyranoside 


\section{Compound $\mathrm{AM}_{103}$}

Compound $\mathrm{AM}_{103}$ was isolated during the isolation of saponin by Roth Rock et. al Method. ${ }^{8}$ The compound was soluble in chloroform and methanol solution. A single spot was observed on TLC developed in $10 \%$ acetone in pet. ether $\left(\mathrm{R}_{\mathrm{f}}=0.5\right)$. It was found to melt at $200^{\circ} \mathrm{C}$. The compound was identified as diosgenin by Co-TLC with authentic sample.

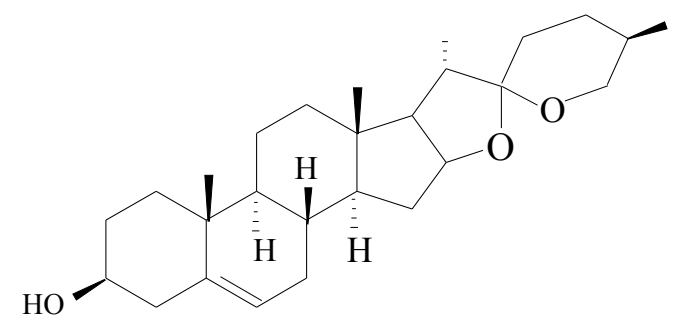

Diosgenin

\section{Estimation of saponin}

Estimation of saponin was carried out on root of Asparagus racemosus by Roth Rock et. al Method. ${ }^{8}$ The percentage of saponin was found to be 0.58 , which seems quite small amount.

\section{Conclusion}

On the basis of above study, methanol extract of $A$. racemosus was identified to have antimicrobial activity which supports its therapeutic value as describe in various literature. This study results into the isolation of compounds which were identified to be 9-hexadecanoic acid-9-octadecenylester (Z,Z), $\beta$ sitosterol, stigmasterol-3-O- $\beta$-D-glucopyranoside and diosgenin. In addition to this, saponin percentage on the root was estimated, which was found to be 0.58 .

\section{Acknowledgement}

We are grateful to Central Department of Chemistry of Tribhuvan University for providing laboratory facilities. The authors are thankful to Mr. Naresh Maharjan of Central Department of Microbiology, Tribhuvan University to carry antimicrobial activity and Dr. Achyut Adhikari of HEJ Reasearch Institute of Chemistry, University of Karachi, Pakistan, for providing the EI mass analysis of compound AM $_{100}$. Sincere thanks goes to Ms. Shrijana Bhattarai for her best level of support in searching the literature. 


\section{Referances}

1. Goyal, R. K., Singh, J., Lal, H., Asparagus racemosus - An Update, Indian Journal of Medical Science, 57(9): 408-414, 2003.

2. HMG Nepal, Ministry of Forest and Soil Conservation, Department of Forest and Plant Research, Medicinal Plants of Nepal, Thapathali, Kathmandu, 1993.

3. Krishnaraju, A.V., Rao, Taye V.N., Sundararajun, D., Vanisree, M., Tsay, H. S., Subbaraju, G.V., Biological Screening of medicinal plants collected from eastern ghats of India using Artemia salina (Brine Shrimp Test), International Journal of Applied Science and Engineering, 4(2): 115-125, 2006.

4. Tip-pyang, S., Tangpraprutgnl, P., Winoonpun, N., Veerachatu, G., Phaupraisairisan, P., Preecha, S. et. al., Aaparagamine A, an invivo anti-oxytocin and anti tumor alkaloid from Asparagus racemosus, Chemical Abstract, 135: 205022m, 2001.

5. Hamal, S., Phytochemical and Biological Studies on Sarcococca hookeriana (Baillon), [M. Sc. dissertation]. Central Department of Chemistry: Tribhuvan University; 2006.

6 Sapkota, R., Phytochemical and Biological Studies on Floral parts of Nepalese Origin Oroxylum Indicum, [M. Sc. dissertation]. Central Department of Chemistry: Tribhuvan University; 2007.

7. Ghimire, B., Phytochemical and Biological Studies on Lyonia oveliplia, [M.Sc. dissertation]. Central Department of Chemistry: Tribhuvan University; 2007.

8. Rothrock, J. W., Hammes, P. A. and McAleer, W. J., Isolation of diosgenin by acid hydrolysis of saponin, Ind. Eng. Chem. Res., 49: 186-188, 1957.

9. Manandhar, E. Phytochemical and Biological Studies on Root and Rhizomes of Nepalese Origin Dioscorea nepalensi [M.Sc dissertation]. Central Department of Chemistry: Tribhuvan University; 2004.

10. Meyer, B. N., Ferrigni, N. R., Putnam J. E., Jacobson, L. B., Nichols, D. E., McLaughlin, J. L., Bine shrimp: a convenient general bioassay for active plant constituents, Planta Medica, 45: 31-34, 1982. 